(2) A lining or luting applied to the inside of such crucible so as to necessitate the passage of the decomposing current through . the melted mass to be treated.

(3) The combination with such a crucible of an external source of heat.

(4) The combination with the fused ore, contained in the crucible before mentioned, of the electrodes of a fairly powerful voltaic battery, or other electric source, so connected with the crucible as to permit the current to pass through the fused mass.

Cintral, High School,

Pinla derphita, Febmaty $3,1888$.

THE WEISBACH SYSTEM OF ILLUMINATION.

By A. O. Granger.

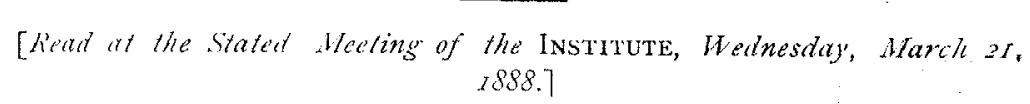

W. P. Tatham, Vice-President, in the Chair.

About the year 18\&0, Carl Auer, then a pupil of Prof. Bunsen at the University of Heidelberg, became interested in the subject of illumination. Bunsen particularly impressed upon Auer's mind that the present method of obtaining illumination from combustion of gas in the ordinary way, in which the separated carbon particles are made incandescent through the heat produced by the combustion of the hydrogen, was far from being economical, inasmuch as the amount of light yielded was but a small percentage of the energy contained in the gas, and gave it as his opinion that the light of the future would be obtained by first converting the illuminating gas into a heating flame through the medium of the well-known burner bearing his name, and then applying the heat so produced to bring to incandescence some refractory material. Young Auer revolved this suggestion in his mind, but before he had succeeded in obtaining any practical result the electric light changed the current of his thoughts. As is well known, in order to produce the incandescent electric light it is necessary that the carbon filament be uséd in a vacuum. Aucr saw the expensiveness of this method, 
and began a series of experiments to produce a flament made from refractory earths or oxides that could be used in the open air without being consumed. It was while engaged upon experiments of this nature that he produced the incandescent gas light now before you.

We all know that the idea of an incandescent light is not new, and every school-boy knows of the Drummond oxy-hydrogen lime light, but all lights of that character have failed to come into commercial use, because the material to be acted upon by the heat has always been present in considerable mass, and has required gas under pressure and a very high temperature to bring the mass to incandescence. But the Welsbach light is successful, because the oxides are produced in an extremely thin or attenuated form whereby the minimum of heat will produce the maximum of light.

Here is a complete burner, Fig. I (see frontispicce). I will light it with the electric taper, and, of course, when that can be used, a match or any other competent source of heat will ignite the gas. You see, there is practically no explosion; in fact, there is less noise than in lighting an Argand burner.

I will describe the Welsbach burner very briefly: We use a modified, but very perfect form of the Bunsen burner (Fig. 2), the heat from which brings to incandescence the hood or mantle. This mantle, such as we have here (exhibiting), is knitted by machinery from fine cotton thread into a cylinder about 2 inches in diameter by 5 inches long. You see, it is soft and limp (Fig. 3). It is then dipped to the point of complete saturation in the chemical solution, which I will presently refer to, and then it is dried and attached by means of fine platinum wire to this vertical iron rod (exhibiting), with the horizontal loop at the top. Here is a mantle that has been saturated (exhibiting) and is all ready for the burning-out process, which consists in holding it over a Bunsen or a water-gas flame, whereby the cotton fibre is completely consumed, leaving nothing but the oxides that had adhered to the cotton (shrunken to about half the former size of the mantle, see Fig. 4) in the form of an extremely fine but coherent and refractory mineral skeleton, which perfectly retains the texture of the woven fabric. This is one of the great secrets of the success of the Welsbach system; no other method that at all approaches this having ever been discovered whereby an extremely small 
amount of refractory material can be made to cover in a practical way so much surface.

There are three principal elements used in the manufacture of the solution in which the cotton cylinder or mantle is dipped, viz: lanthanum, zirconium and yttrium. These are produced respectively from the minerals cerite, zircon and samarskite, which are found in large quantities in Norway, Sweden, Ceylon, the Ural Mountains, and in our own country in North Carolina and elsewhere.

We have here some fine samples of the ores or minerals, and I will be glad to have anyone interested inspect them, as also the burners, etc., at the close of the meeting.

Herctofore these minerals have been considered very rare, and so they were so long as the only demand for them was for the collections of chemists and mineralogists. Now we can produce these crystals by the shovelful, and the cost of the oxides in one of these beautiful burners is but a few cents.

I will not weary you with the details of the method of reducing the ores to obtain these oxides as nearly chemically pure as possible, and will merely state that the result of the various operations employed is before us in the impalpable powder, of which we have here (exhibiting) a good sample, and from which the final impregnating solution is made by using certain proportions of the minerals.

Here is a bottle of the solution (exhibiting). It has a milky look, as you see, rather like lime water, and it is only necessary to vary the proportions of the oxides to produce any light from an intense white to a brilliant yellow.

The Welsbach patents were first acquired by the United Gas Improvement Company, of this city, and the original purchasers afterwards formed the Welsbach Company that now owns the system for the United States. It was early determined, after the managers had been fully satisfied in every particular as to the burner, to lay out plans and make an investment on a generous scale, and not to put any burners on the market until a considerable stock had been accumulated, so as to meet the large demand that was sure to come.

The Welsbach Incandescent Gas Light Company has a large factory at Gloucester, N. J., where the buildings cover some three 
acres of ground. The company is introducing machinery and organizing its force to make 25,000 to 30,000 complete burners per day. It has erected its own fuel gas works, and, besides the machinery and apparatus for reducing minerals, has a complete chemical laboratory, machine shop, elaborate photometrical rooms, etc.

The working force is so organized that each step in the manu. facture is carried on in a separate room. First comes the knitting of the mantle by machinery, and then a corps of girls attend to what is called the rcinforcing or folding the mantle over at the top so as to have a larger amount of material through which to thread the platinum wire from which the mantle is suspended. The mantle is dipped in the solution and goes through a drying room, and then to the forming room, where it is given its shape, and then to the burning-out room, where the cotton is entirely consumed, leaving the refractory skeleton of the fabric behind, preserving intact the shape and appearance of the knitted cotton mantle. It is then mounted on the brass work or gallery, and we have the complete burner. For purposes of shipment the mantle, after having been burned as described, is dipped in a solution that entirely prevents any damage in transit.

Now, in introducing any new system of illumination, there are certain conditions necessary to success, and they must be recognized and fully covered.

(1) The brackets, chandeliers and gas fixtures that are in ordinary use must not be interfered with in any material way, and illustrating this point I will ask my assistant, Mr. Crisfield, to put one of these burners on that bracket on the wall (indicating).

There is an ordinary bracket, and an old-fashioned gas burner. You will see the facility with which the old burner is taken off and the Welsbach burner put on, only a few moments of time being required. (The change was made as $\mathrm{Mr}$. Granger spoke.)

(2) The new burners must give a brighter, steadier and in every way a better light than the ordinary gas flame, so that the improvement will be decided at once upon seeing it. I think that point has also been covered and must be apparent to all present. (Pointing to the burners.)

Relative to the feature of economy, of which I will speak a little later, I will ask Dr. Wahl to kindly take a reading of these 
burners to find the amount of gas used by the Welsbach and by the ordinary jet. Here is the meter and stop-watch.

While Dr. Wahl was making the reading Mr. Granger continued):

(3) Any new burner coming before the public must also be easily lighted, easily taken care of, not liable to special derangement in ordinary practice or handling, and the cost of renewals must be moderate. This burner, while it is a mere skeleton, a mere ash, will stand all the banging it would get in ordinary use, and can be lighted just as easily as an Argand burner, with a match, or in any other way. (Illustrating by vigorously shaking a burner and then lighting it with an electric taper.)

(4) There should also be-and this point should be marked wcll-less vitiation of the atmosphere of the room. We all know that the combustion of gas in the ordinary way is imperfect, resulting in considerable vitiation of the atmosphere, and particles of carbon are set free as smoke or soot, but with the Bunsen flame this great objection is done away with, and there is also less oxygen consumed by reason of the reduced amount of gas burned.

(5) And above all, economy. While we may have a light that will radiate less heat-one that will give a perfectly white light, so that colors can be detected at night-a steady light, not affected by draughts, and a light that is more beneficial to health and in every way pleasanter and more desirable-yet if it possesses no economy in the use of gas, it will not find public favor to a large extent. In this burner we have no hesitation in asserting that with any kind of illuminating gas there is an efficiency of at least two to one in favor of the Welsbach burner. In other words, two and a half feet of coal gas consumed with the Welsbach burner will give a better light than five to six feet of gas consumed in the ordinary way. Now, to apply that practically in Philadelphia: Our coal gas is sold at \$I.50 per 1,000 feet. With the Welsbach burner the gas would be less than seventy-five cents. That's not very scientific, but it is eminently practical.

Dr. Wahl says the ordinary gas jet is burning nearly eight feet, while about two and three-quarter feet are being consumed by this Nelsbach burner.

[Although the meter reading had been made with great care, Dr. Wahl, being surprised at the result, said he would like to take 
another reading of the ordinary gas jet, causing $\mathrm{Mr}$. Granger to exclaim sotto-7oce, "Give the gas a chance," which was received with much laughter.]

Dr. Goldsumin :--I would like to ask how you account for the cohesion? Is there an interlocking of the particles, or fusion?

Mr. GRANGER:-No, there is no fusion. As you see, this mantle is a reticulated mesh work, and when the cotton is entirely burned away, we have a perfect oxide copy of its former shape-a mere shadow, but thcre is, nevertheless, a certain amount of cohesion of the particles that make them hold together.

Dr. Golosmirn :--That is what I wanted to get at.

Mr. Grancill :- That is one of the great points in this system. Others have attempted to produce an incandescent light, but the material while enduring a few hours, would disintegrate and fall to pieces, but there are certain clements used in the manufacture of this solution that give a toughness to the mantle which is very remarkable.

Dr. Goldsmin:-I can readily understand it if any fusion takes place of any elements, but it puzzled me to see how they otherwise held together, at first.

Mr. Granger:- It is a decided advance, and is only accomplished by certain chemicals that produce that result. There is, however, no fusion of the particles. We have not heat enough in the gas flame to fuse them.

Dr. WAHL:- The meter readings hold about the same relation to each other as before.

Mr. Granger:-While Dr. Wahl is completing that reading, I would say that I was recently in New York City, at the home of a friend, who is a Director of the Welsbach Incandescent Gas Light Company of New York, and he had on a side wall-bracket two Welsbach burners, each in a shade or globe similar to this (indicating), and below the bracket was a decorated plate (or plaque as I suppose the ladies would call it), set in a velvet frame, and this was hanging from the gas bracket by a little silvered wire, and a friend was there looking at the beautiful light. He seemed a good deal puzzled-looked at it a moment, and then said: "Does the current come up these wires?" (Merriment.)

A Member:-What is the average life of the mantle? 
Mr. GRANGFR:-About 500 to I,O00 hours, or about six months of ordinary use, represented by the 500 hours.

1 would like also to refer to one other point. I have a letter herc from Prof. A. M. Mayer, of the Stevens Institute of Technology, whom many of you doubtless know, addressed to Mr. Shapleigh, who is the superintendent and chemist of the Welsbach Company's works at Gloucester. He says:

"One of the Welsbach burners I had handed me by Prof. Morton, who has several of them. I have been making experiments on it. Among other valuable properties for a lecturer and for researches in physics is the fact that it has furnished me at last, after many trials with other sources of radiant heat, with a source which is so constant that when placed before a Melloni thermo-pile it causes a deflection of the Thomson galvanometer (connected with the pile) which is absolutely constant, so that the reflected beam of light from the galvanometer remains in one fixed position on the screen. "This lamp will hereafter be a requisite for all of these thermo-electric instruments."

I will now light the different burners so that you can see the variation in color. We have hardly pressure enough here to run all the burners, the gas having to pass through the rubber tube and test meter, but you see there is a white light, and this is the yellow. I will light this one so that you can see the effect of the globe or shade. (Does so.)

Dr. WaHL:-I would like to ask whether you have experimented as to the resistance of the filament to withstand a jar or shock given to the brackets, to determine whether or not by any accidental shaking, or any knock that it would be likely to get in use, it would be injured?

Mr. Granger:-In reply to that question I would say that I recently saw a statement made by the editor of a London scientific journal that he understood these mantles to be so fragile, that the least vibration, even that amount produced by a heavily-loaded team passing in the street, would disintegrate the mantle. This is the best answer to that statement (tapping the burner sharply several times), and I don't think that in ordinary use, unless a person went at it intending to break it, it would ever receive rougher handling than $I$ have just given it, and so we hold that it is practical for ordinary use.

I would also say that this burner is quite an improvement over the burner that was brought to the attention of the United Gas Improvement Company a year ago. Then. a chimney was required 
several inches taller than this, and of the pattern or style known as the student lamp chimney, having a constricted portion here (indicating), and the burncr was rather troublesome to light, requiring some skill. You had to turn it just so, and put the match at the right place just at the right time; but all that has been overcome now, and we use the Argand chimney of commerce; you can light it and use it just the same as any other burner, and hence we feel that it is now a practical success. I would say for the information of my hearers that in a few wceks the Philadelphia Welsbach Company will open its rooms at 122 South Twellth Street, where there will be a number of burners on exhibition, both white and yellow, and also burners used with fuel gas.

We have here a small tank of fucl water gas (hydrogen and carbonic oxide) made at our works in Gloucester, from the decomposition of steam by passing it through a bed of glowing anthracite coal. I will ask my assistant, Mr. Beard, to turn on the gas, so that we can light this burner. (Exhibits the burner with fuel gas.)

Dr. WaHL (noticing the ease with which Mr. Granger lighted the burner from the top) said: "It seems to me that one of the best evidences of the practicability of the Welsbach filament is the fact that it can be lighted from above. There is a certain amount of explosive mixture formed in that chimney, and, as is well known, when the attempt is made to light it, it ignites with a slight explosion-and the fact that the filament will stand that sort of treatment seems to me a point in its favor. I am surprised to sce the filament holding out and behaving as it does, because in reading of it I was led to believe that it was extremely fragile.

Mr. GRangris:- We have here a very good form of Prof. Bunsen's burner, with a modified tip, so that there is almost no aulible explosion and we are not troubled with lighting back, which is a very great fault in the ordinary Bunsen. There (pointing) we have a fine light with the fuel gas, and we have made experiments with this burner with natural gas, and find, in Pittsburgh, that we get twelve candles per foot. From the ordinary city gas here (coal gas) we get about eight candles per foot, so that the rarge may be said to be from eight candles per foot with coal sas to twelve candles per foot with natural gas. We have also tested it with gas produced by the Springfield and other gas machines, and get practically the same result as we have here, 
showing that the burner is adapted to anything in the way of vapor or gas that contains sufficient heat.

Photographs have also been taken at night with this burner, and with an exposure of from one and a half to two minutes, negatives have been produced equal in every particular to the best sun negatives, showing that the actinic properties of the light are very perfect.

Mr. TATHAM:- How low can you turn it down without putting it out?

[Mr. Granger turned a burner down so low that some person in the audience said: "It's out." But it was not out, as was shown by turning the gas on, when the brilliant light instantly reappeared.]

Mr. Ives then projected the burner and mantle on the screen, sreatly enlarged, after which the discussion was closed.

\section{GENERAL THEORY OF JOINTED BOW GIRDERS.}

By E. A. Werner, C.E.

\section{PART I.-EXTERNAL FORCES.}

Any structure is a system of material points acted upon by external and internal or elastical forces, which is subject to certain conditions-in our case to the condition to remain on certain points or planes-the abutments. All the forces acting upon the structure must be in equilibrium, when the structure shall resist the action of these forces.

Now, we know that the conditions of equilibrium of a free, rigid system of material points acted upon by forces can be expressed mathematically and that any system can be turied into a free, rigid system, in making the forces homogeneous and replacing the conditions to which it might be subject by forces of the same kind.

Hence in order to apply to any structure mathematical calculation, it is necessary to transform it into a free, rigid system, by expressing the internal or elastical forces and the conditions, that the structure has to remain upon the abutments by external, forces. 